\title{
Adaptive Command-Filtered Backstepping Control for Linear Induction Motor via Projection Algorithm
}

\author{
Wenxu Yan, Jie Huang, and Dezhi Xu \\ Institute of Electrical Engineering and Intelligent Equipment, School of Internet of Things Engineering, Jiangnan University, \\ Wuxi 214122, China \\ Correspondence should be addressed to Dezhi Xu; lutxdz@126.com
}

Received 6 May 2016; Revised 19 August 2016; Accepted 22 August 2016

Academic Editor: Xuejun Xie

Copyright (C) 2016 Wenxu Yan et al. This is an open access article distributed under the Creative Commons Attribution License, which permits unrestricted use, distribution, and reproduction in any medium, provided the original work is properly cited.

\begin{abstract}
A theoretical framework of the position control for linear induction motors (LIM) has been proposed. First, indirect field-oriented control of LIM is described. Then, the backstepping approach is used to ensure the convergence and robustness of the proposed control scheme against the external time-varying disturbances via Lyapunov stability theory. At the same time, in order to solve the differential expansion and the control saturation problems in the traditional backstepping, command filter is designed in the control and compensating signals are presented to eliminate the influence of the errors caused by command filters. Next, unknown total mass of the mover, viscous friction, and load disturbances are estimated by the projection-based adaptive law which bounds the estimated function and simultaneously guarantees the robustness of the proposed controller against the parameter uncertainties. Finally, simulation results are given to illustrate the validity and potential of the designed control scheme.
\end{abstract}

\section{Introduction}

In the past two decades, linear induction motors (LIM) have been broadly used in all walks of life, such as the military, life electric, industrial automation, and transportation, which all have satisfactory performance [1-7]. The most significant advantage of LIM is that it can provide linear motion without any medium machine. Moreover, there are many advantages in LIM, such as simple structure, high-starting thrust force, low noise, high-speed operation, reduction of mechanical losses, and being without any gear between motors and motion devices $[8,9]$, and as counterpart these advantages introduce the disadvantages of the complicated LIM model presenting the complexity of the control characteristics. Although the driving principles of the LIM and the conventional rotary induction motor (RIM) are actually similar, the control scheme of the LIM is even more intricate than that of the traditional RIM, reason for which is that the parameters of the LIM are time-varying in the process of operation, such as rail configuration, speed of the mover, and temperature [10]. Furthermore, there are more important parameter variations in end effect, slip frequency, saturation of the magnetizing inductance, phase unbalance, and dynamics of the air gap [11, 12], and, because of this, it is hard to get the complete mathematical model of LIM. Despite the fact that the consideration of significant variations for the model of the dynamic performance of the LIM has been researched [11-14], the control performance of LIM is still influenced by uncertainties such as nonlinear dynamics, unknown external load disturbances, and irregular plant parameter variations. The main purpose of this paper is to design a suitable control scheme to deal with the uncertainties existing in the dynamic model of LIM.

In the past decade, indirect field-oriented control (IFOC) technique has been one of the prevalent control techniques widely implemented in industrial LIM drives and it has been proved that it is appropriate for a wide range of technological applications. The main idea of IFOC is to decouple torque and flux, which can be implemented by forcing the secondary flux of the $d$-axis to be a constant and setting the secondary flux of the $q$-axis to zero. Through this method, the system structure can be simplified. However, the performance of the system is sensitive to the variations of motor parameters and the rotor time constant which fluctuates notably with the saturation of the magnetizing inductance and the temperature [14]. 
Due to the rapid development of nonlinear control theory, backstepping is one of the nonlinear control techniques developed in the 1990s [15] to stabilize the nonlinear dynamic system [16-18], which has been used for the LIM [19, 20]. The backstepping control is a recursive structure, so the design process can be started at the known-stable system and back out new controllers that progressively stabilize each outer subsystem. Although the backstepping alleviates some limitations of other methods and provides an option of design tools to accommodate nonlinearities in the design of the controller, the traditional backstepping requires that exact information of the model is obtained and the parameter uncertainties are not taken into consideration [21]. In order to ensure the stability of most control systems with nonlinearities and parameter uncertainties, adaptive backstepping approach has been investigated, which has been proved to be effective to achieve the satisfactory control performance [10, 14, 22-25]. However, there is a problem called "explosion of terms" in backstepping. That is to say, in the design process of each subsystem, virtual control commands need to be differentiated repeatedly. With the increase of the number of the system orders, it is difficult or even impossible to derive the analytical differential expression of virtual control, so this problem limits the application of backstepping method used in practical engineering. The rest of the problems in backstepping have the following two main points: control saturation problem and the fact that the system must be simplified into the form of parametric strict feedback. In particular the previous drawback may result in some fateful problems in the actual control system, because accumulation of errors may cause system instability if the generated control signal commands are not completely executed by actuators. At present, there are many methods to solve the above-mentioned defects such as dynamic surface control [26] and command-filtered method [27-30], and among them command-filtered backstepping is a more effective way compared to dynamic surface control. Dynamic surface control uses the filter to solve the differential expansion problem, but the introduction of the filter can only ensure that the system is bounded tracking. However, the command-filtered backstepping controller can solve the problem of differential expansion, and it can also realize the asymptotic tracking of the closed-loop signal due to the filter compensation.

In this paper, a command-filtered adaptive backstepping control via projection algorithm designed on indirect field orientation is proposed for the LIM to achieve a position tracking objective under the disturbance of load thrust force and parameter uncertainties. At the same time, Lyapunov stability theory is used to prove that the control system can be maintained closed-loop asymptotically stable. The rest of this paper is organized as follows. In Section 2, the principle of indirect field-oriented control applied to LIM is derived. Section 3 presents the command-filtered adaptive backstepping controller designed for LIM position control via projection algorithm. In Section 4, simulation results are showed to prove the validity of the proposed control scheme. Finally, we come to some conclusions at the end of this paper.

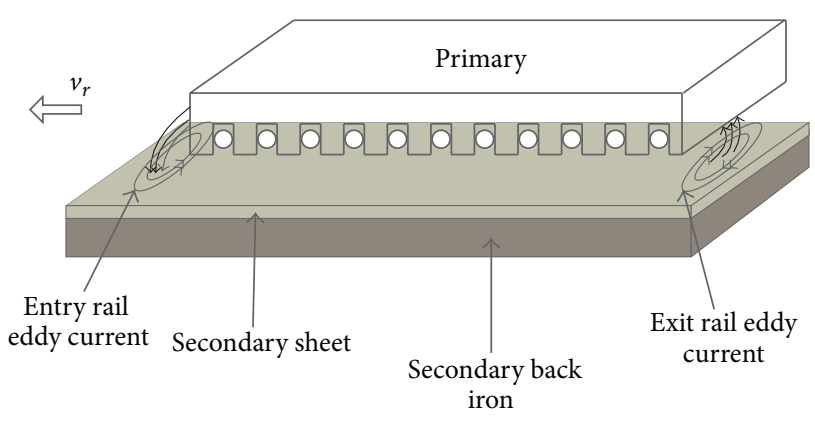

FIgURE 1: Structure of a LIM.

\section{Indirect Field-Oriented Control of LIM}

The LIM is formed by the primary and secondary, which is shown in Figure 1. The primary of the adopted threephase LIM is the primary of rotary-motor simply cut open and rolled flat. The secondary usually consists of a sheet conductor using aluminum with an iron back for the return path of magnetic flux. Moreover, a simple linear encoder is adopted for the feedback of the mover position $[12,20]$. When the current flowing primary produces a magnetic field though the primary from front to back, the eddy currents are generated on the surface the secondary by this magnetic field. When the primary of the LIM is still, the equivalent circuit of LIM is similar to the rotating motor. However, with the primary moving, the secondary is constantly replaced with new secondary sheet which will resist a sudden increase in flux and only allow the gradual establishment of magnetic flux in air gap. On the contrary, the field in the exit side of the rail will disappear quickly. The phenomenon affecting the air gap flux distribution happens at the entry and exit of the primary called end effect. The parameter $Q$ is used to simulate the end effect expressed as $[11,20]$

$$
Q=\frac{l \cdot R_{r}}{L_{r} \cdot v_{r}},
$$

where $v_{r}$ is the mover linear velocity, $l$ is the primary length, $L_{r}$ is the secondary inductance per phase, and $R_{r}$ is the secondary resistance per phase. Then, the inductance can be expressed as

$$
\begin{gathered}
L_{m}^{\prime}=L_{m}(Q)=L_{m}(1-f(Q)), \\
L_{r}^{\prime}=L_{r}(Q)=L_{r}-L_{m} f(Q), \\
L_{s}^{\prime}=L_{s}(Q)=L_{s}-L_{m} f(Q),
\end{gathered}
$$

where $f(Q)=1-e^{-Q} / Q, L_{m}$ is the magnetizing inductance per phase, $L_{s}$ is the primary inductance per phase, and $L_{r}$ is the secondary inductance per phase. And the secondary time constant is expressed by

$$
T_{r}^{\prime}=\frac{L_{r}^{\prime}}{R_{r}}=\frac{L_{r}-L_{m} f(Q)}{R_{r}} .
$$

Based on the above description, we can see that the shorter the primary length and the higher the motor speed, 


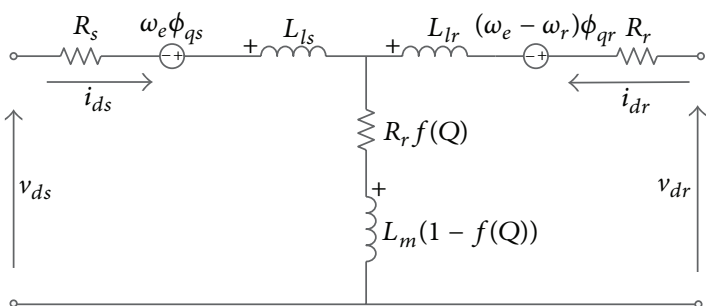

(a) $d$-axis equivalent circuit

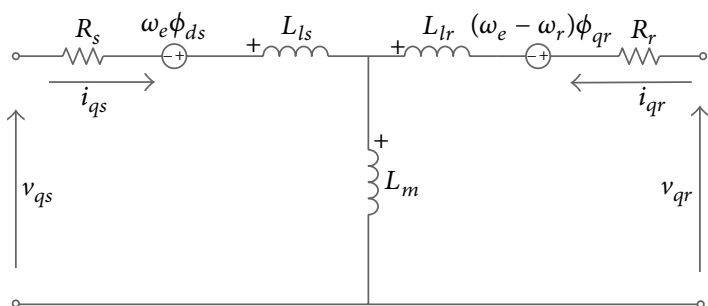

(b) q-axis equivalent circuit

FIgURE 2: The equivalent circuits of the LIM considering the end effect.

the lower the factor $Q$. It means that end effect is mainly dependent on the linear motor speed in a certain LIM.

The dynamic model of the LIM considering the end effect is researched by using $d-q$ axis theory shown in Figure 2 . From the equivalent circuit of the LIM, we can find that the $q$ axis equivalent circuit of the LIM is different from the RIM, but the $d$-axis equivalent of LIM and RIM is the same [20]. According to the dynamic model of the LIM, the voltage equations can be drawn as follows:

$$
\begin{aligned}
& v_{d s}=R_{s} i_{d s}+R_{r} f(Q)\left(i_{d s}+i_{d r}\right)+p \phi_{d s}-\omega_{e} \phi_{q s}, \\
& v_{q s}=R_{s} i_{q s}+p \phi_{q s}+\omega_{e} \phi_{d s}, \\
& v_{d r}=R_{r} i_{d r}+R_{r} f(Q)\left(i_{d s}+i_{d r}\right)+p \phi_{d r}-\omega_{s \mathrm{l}} \phi_{q r}=0, \\
& v_{q r}=R_{r} i_{q r}+p \phi_{q r}+\omega_{s \mathrm{~s}} \phi_{d r}=0 .
\end{aligned}
$$

And the linkage fluxes are expressed by the following equations:

$$
\begin{aligned}
& \phi_{d s}=L_{l s} i_{d s}+L_{m}^{\prime}\left(i_{d s}+i_{d r}\right), \\
& \phi_{q s}=L_{l s} i_{q s}+L_{m}\left(i_{q s}+i_{q r}\right), \\
& \phi_{d r}=L_{l r} i_{d r}+L_{m}^{\prime}\left(i_{d s}+i_{d r}\right), \\
& \phi_{q r}=L_{l r} i_{q r}+L_{m}\left(i_{q s}+i_{q r}\right)=0 .
\end{aligned}
$$

The purpose of this paper is to design a satisfactory controller to deal with the uncertainties existing in the simplified dynamic model of LIM, so the simplified dynamic model of the LIM is researched by using $d-q$ axis theory and is modified from the traditional model of a three-phase, Yconnected induction motor in $d-q$ stationary frame, which can be described by the following differential equations [10, $13,19,20]$ :

$$
\begin{aligned}
& \frac{d i_{d s}}{d t}=\frac{1}{\sigma L_{s}}\left(-\left(R_{s}+\left(\frac{L_{m}}{L_{r}}\right)^{2} R_{r}\right) i_{d s}+\sigma L_{s} \frac{\pi}{h} v_{e} i_{q s}\right. \\
& \left.+\frac{L_{m} R_{r}}{L_{r}^{2}} \phi_{d r}+\frac{P L_{m} \pi}{L_{r} h} \phi_{q r} v_{r}+v_{d s}\right), \\
& \frac{d i_{q s}}{d t}=\frac{1}{\sigma L_{s}}\left(-\sigma L_{s} \frac{\pi}{h} v_{e} i_{d s}-\left(R_{s}+\left(\frac{L_{m}}{L_{r}}\right)^{2} R_{r}\right) i_{q s}\right. \\
& \left.\quad-\frac{P L_{m} \pi}{L_{r} h} \phi_{d r} v_{r}+v_{q s}\right),
\end{aligned}
$$

$$
\begin{aligned}
& \frac{d \phi_{d r}}{d t}=\frac{L_{m} R_{r}}{L_{r}} i_{d s}-\frac{R_{r}}{L_{r}} \phi_{d r}+\left(\frac{\pi}{h} v_{e}-P \frac{\pi}{h} v_{r}\right) \phi_{q r}, \\
& \frac{d \phi_{q r}}{d t}=\frac{L_{m} R_{r}}{L_{r}} i_{q s}-\frac{R_{r}}{L_{r}} \phi_{q r}-\left(\frac{\pi}{h} v_{e}-P \frac{\pi}{h} v_{r}\right) \phi_{d r}, \\
& F_{e}=K_{f}\left(\phi_{d r} \cdot i_{q s}-\phi_{q r} \cdot i_{d s}\right)=M \cdot \dot{v}_{r}+D \cdot v_{r}+F_{L},
\end{aligned}
$$

where $R_{s}$ is the winding resistance per phase, $h$ is the pole pitch, $P$ is the number of pole pairs, $\phi_{d r}$ and $\phi_{q r}$ are $d$-axis and $q$-axis secondary flux, respectively, $i_{d s}$ and $i_{q s}$ are $d$-axis and $q$-axis primary current, respectively, $v_{d s}$ and $v_{q s}$ are $d$-axis and $q$-axis primary voltage, respectively, $\omega_{\text {sl }}=\omega_{e}-\omega_{l}$ is the slip frequency, $K_{f}=3 P \pi L_{m} /\left(2 h L_{r}\right)$ is the force constant, $F_{e}$ is the electromagnetic force, $F_{L}$ is the external force disturbance, $M$ is the total mass of the moving element, and $D$ is the viscous friction and iron-loss coefficient.

Then, in indirect field-oriented control, the reference frame is aligned to secondary flux, so the flux equations are described as follows:

$$
\begin{aligned}
& \phi_{q r}=\dot{\phi}_{q r}=0, \\
& \phi_{d r}=\phi_{r}=\text { constant. }
\end{aligned}
$$

Moreover, the slip velocity signal can be expressed as

$$
v_{\mathrm{sl}}=\frac{h L_{m}}{\pi T_{r} \phi_{d r}} i_{q s} .
$$

By use of the indirect field-oriented control technique, the electromagnetic force shown in (10) can be reasonably simplified as follows:

$$
\begin{aligned}
F_{e} & =K_{T} \cdot i_{q s}, \\
K_{T} & =\frac{3}{2} P \frac{\pi \cdot L_{m}}{h \cdot L_{r}} \phi_{d r} .
\end{aligned}
$$

From (10) and (13), we have

$$
\dot{v}=\frac{K_{T}}{M} i_{q s}+F v+\Gamma,
$$

where $F=-D / M$ and $\Gamma=-F_{L} / M$.

\section{Adaptive Command-Filtered Backstepping Control via Projection Algorithm}

The LIM with a notable nonlinear performance has many parameters that cannot be known exactly, such as mover 


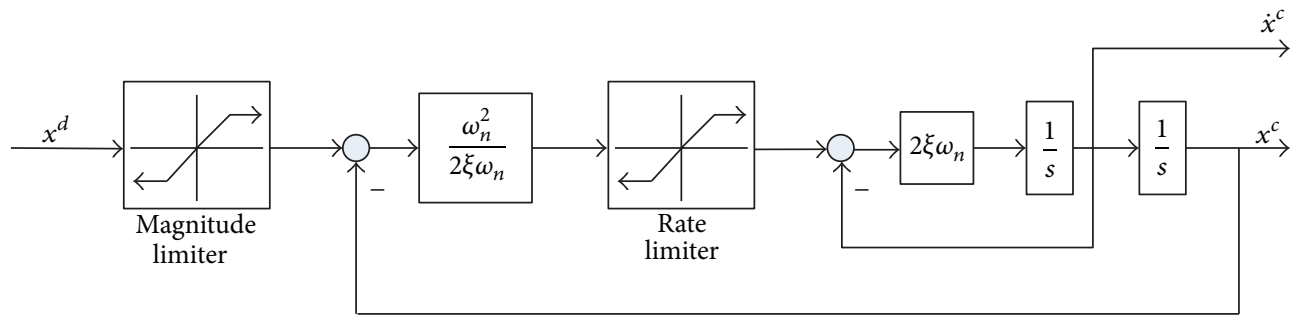

FIGURE 3: Structure of constrained command filter.

mass, friction coefficient, and load torque. The purpose of this paper is to design a suitable control to confront the existing uncertainties that would exist in the simplified dynamic model of the LIM. According to Lyapunov stability principle and adaptive backstepping theory, the satisfactory controller is derived. By use of the command filter, the differential expansion and the control saturation problems in conventional backstepping control have been solved, and compensating signals are meanwhile presented to eliminate the influence of the errors caused by command filters. Because of using the projection-based adaption law, the parameters estimated function can be bounded, and it also guarantees the robustness of the controller against the uncertain disturbances in theory.

In order to achieve the position control of LIM, we choose the mover linear velocity $v$ and $q$-axis current $i_{q s}$ as the control variables. The design of the command-filtered adaptive backstepping control for a LIM mover position control is deduced step by step as follows.

Step 1. The tracking error variables $e_{1}(t), e_{2}(t)$, and $e_{3}(t)$ are defined as follows:

$$
\begin{aligned}
& e_{1}(t)=d(t)-d^{c}(t), \\
& e_{2}(t)=v(t)-v^{c}(t), \\
& e_{3}(t)=i_{q s}(t)-i_{q s}^{c}(t),
\end{aligned}
$$

where $d^{c}(t)$ is the input reference position and $v^{c}(t)$ and $i_{q s}^{c}(t)$ are the filtered command of $d(t), v(t)$, and $i_{q s}(t)$, correspondingly. The structure of command filter is shown in Figure 3.

From (14) and (15), the time derivative of the tracking errors can be calculated as follows:

$$
\begin{aligned}
& \dot{e}_{1}(t)=v(t)-\dot{d}^{c}(t), \\
& \dot{e}_{2}(t)=\frac{K_{T}}{M} i_{q s}(t)+F v(t)+\Gamma-\dot{v}^{c}(t), \\
& \dot{e}_{3}(t)=\dot{i}_{q s}(t)-\dot{i}_{q s}^{c}(t) .
\end{aligned}
$$

Step 2. The task is to stabilize (16) with respect to the Lyapunov function:

$$
V_{1}=\frac{1}{2} e_{1}^{2}(t)
$$
by

And the time derivative of $V_{1}$ with respect to time is given

$$
\begin{aligned}
\dot{V}_{1} & =e_{1}(t) \dot{e}_{1}(t)=e_{1}(t)\left(v(t)-\dot{d}^{c}(t)\right) \\
& =-k_{1} e_{1}^{2}(t)+e_{1}(t)\left(k_{1} e_{1}(t)+v(t)-\dot{d}^{c}(t)\right) .
\end{aligned}
$$

So the virtual controller can be considered as

$$
v^{d}(t)=\dot{d}^{c}(t)-k_{1} e_{1}(t)
$$

where $v^{d}(t)$ is the desired velocity and $k_{1}>0$ is a design constant. Substituting (21) into (20), we have $\dot{V}_{1}<0$. Thus, based on Lyapunov stability theory, the virtual control is asymptotically stable.

In order to solve the problems of differential expansion and the control saturation, a command filter is used to eliminate the impact of time derivative of (21) and control saturation. Passing $v^{d}$ through a filter, which is shown in Figure 3, the state-space model of command filter can be described as [27-30]

$$
\left[\begin{array}{c}
\dot{q}_{1} \\
\dot{q}_{2}
\end{array}\right]=\left[2 \xi \omega_{n}\left[S_{R}\left(\frac{\omega_{n}^{2}}{2 \xi \omega_{n}}\left(S_{M}(u)-q_{1}\right)\right)-q_{2}\right]\right]
$$

where $u=x^{d}$ is the input of the command filter, $S_{R}(\cdot)$ and $S_{M}(\cdot)$ express the rate and magnitude limit functions, respectively, and $\xi$ and $\omega_{n}$ are the damping and the bandwidth of the filter, respectively.

It is worth noting that the command filter will produce a filtering error which may increase the difficulty in getting the tiny tracking error. So we redefine tracking error as $\bar{e}_{1}(t)=$ $e_{1}(t)-\varepsilon_{1}(t)$, and design compensating signals given by

$$
\dot{\varepsilon}_{1}(t)=-k_{1} \varepsilon_{1}(t)+\left(v^{c}(t)-v^{d}(t)\right) .
$$

Step 3. To stabilize (17), we choose the Lyapunov function:

$$
V_{2}=\frac{1}{2} \bar{e}_{1}^{2}(t)+\frac{1}{2} e_{2}^{2}(t) .
$$

The derivative of $V_{2}$ along the trajectory of the error dynamical equations is

$$
\dot{V}_{2}=\bar{e}_{1}(t) \dot{\bar{e}}_{1}(t)+e_{2}(t) \dot{e}_{2}(t) .
$$


According to (16), (21), and (23), the derivative equation for $\bar{e}_{1}(t)$ is calculated as

$$
\begin{aligned}
\dot{\bar{e}}_{1}= & v(t)-\dot{d}^{c}(t)+k_{1} \varepsilon_{1}(t) \\
& -\left(v^{c}(t)+k_{1} e_{1}(t)-\dot{d}^{c}(t)\right)=e_{2}(t)-k_{1} \bar{e}_{1}(t) .
\end{aligned}
$$

Substituting (17) and (26) into (25), we can compute the derivative of $V_{2}$ :

$$
\begin{aligned}
\dot{V}_{2} & =\bar{e}_{1}(t)\left(e_{2}(t)-k_{1} \bar{e}_{1}(t)\right)+e_{2}(t)\left(\frac{K_{T}}{M} i_{q s}(t)\right. \\
& \left.+F v(t)+\Gamma-\dot{v}^{c}(t)\right)=e_{2}(t)\left(\frac{K_{T}}{M} i_{q s}(t)+F v(t)\right. \\
& \left.+\Gamma-\dot{v}^{c}(t)+k_{2} e_{2}(t)+\bar{e}_{1}(t)\right)-k_{1} \bar{e}_{1}^{2}(t)-k_{2} e_{2}^{2}(t),
\end{aligned}
$$

where $k_{2}>0$ is a design constant. And if we choose the virtual control $i_{q s}^{d}(t)$ as

$$
i_{q s}^{d}(t)=\frac{M}{K_{T}}\left(\dot{v}^{c}(t)-F v(t)-\Gamma-k_{2} e_{2}(t)-\bar{e}_{1}(t)\right),
$$

we could get

$$
\dot{V}_{2}=-k_{1} \bar{e}_{1}^{2}(t)-k_{2} e_{2}^{2}(t)<0
$$

So, the virtual control $i_{q s}^{d}(t)$ in (28) is asymptotically stable.

As the parameters $M, F$, and $\Gamma$ are unknown, their estimates $\widehat{M}(t), \widehat{F}(t)$, and $\widehat{\Gamma}(t)$ are used in (28), which is

$$
\begin{aligned}
\widehat{i}_{q s}^{d}(t) & =\frac{\widehat{M}(t)}{K_{T}}\left(\dot{v}^{c}(t)-\widehat{F}(t) v(t)-\widehat{\Gamma}(t)-k_{2} e_{2}(t)\right. \\
- & \left.\bar{e}_{1}(t)\right) .
\end{aligned}
$$

In order to eliminate the impact of derivate of (30) and control saturation, redefine tracking error $\bar{e}_{2}(t)=e_{2}(t)-\varepsilon_{2}(t)$ and design compensating signal as

$$
\dot{\varepsilon}_{2}(t)=-k_{2} \varepsilon_{2}(t)+\frac{K_{T}}{M}\left(i_{q s}^{c}(t)-i_{q s}^{d}(t)\right)
$$

Step 4. Finally, variables $e_{3}$ and $\widehat{M}(t), \widehat{F}(t)$, and $\widehat{\Gamma}(t)$ are added to $V_{2}$ to form the following Lyapunov function:

$$
\begin{aligned}
V_{e} & =\frac{1}{2}\left[\bar{e}_{1}^{2}(t)+\bar{e}_{2}^{2}(t)+e_{3}^{2}(t)+\frac{\widetilde{M}^{2}(t)}{M \gamma_{1}}+\frac{\widetilde{F}^{2}(t)}{\gamma_{2}}\right. \\
& \left.+\frac{\widetilde{\Gamma}^{2}(t)}{\gamma_{3}}\right],
\end{aligned}
$$

where $\gamma_{i}(i=1,2,3)$ are adaptive gains.
According to (17), (30), and (31), we can compute the derivative equation for $\dot{\bar{e}}_{2}(t)$ as

$$
\begin{aligned}
\dot{\bar{e}}_{2}(t)= & \frac{K_{T}}{M} i_{q s}(t)+F v(t)+\Gamma-\dot{v}_{c}(t)+k_{2} \varepsilon_{2}(t) \\
& -\frac{K_{T}}{M} i_{q s}^{c}(t)+\frac{K_{T}}{M} i_{q s}^{d}(t) \\
= & \frac{K_{T}}{M} e_{3}(t)+F v(t)+\Gamma-\dot{v}_{c}(t)+k_{2} \varepsilon_{2}(t) \\
& +\frac{K_{T}}{M} \frac{\widehat{M}(t)}{K_{T}} \phi_{1}(t) \\
= & \frac{K_{T}}{M} e_{3}(t)+F v(t)+\Gamma-\dot{v}_{c}(t)+k_{2} \varepsilon_{2}(t) \\
& +\frac{\widehat{M}(t)-M+M}{M} \phi_{1}(t) \\
= & \frac{K_{T}}{M} e_{3}(t)-\widetilde{F}(t) v(t)-\widetilde{\Gamma}(t)-k_{2} \bar{e}_{2}(t)-\bar{e}_{1}(t) \\
& +\frac{\widetilde{M}(t)}{M} \phi_{1}(t) .
\end{aligned}
$$

Similarly, substituting (7) into (18), we can get the derivative equation for $\dot{e}_{3}(t)$ as

$$
\dot{e}_{3}(t)=\phi_{2}(t)+\frac{v_{q s}(t)}{\sigma L_{s}}-\dot{i}_{q s}^{c}(t),
$$

where $\widetilde{M}=\widehat{M}-M, \widetilde{F}=\widehat{F}-F$, and $\widetilde{\Gamma}=\widehat{\Gamma}-\Gamma$ are the parameter estimation errors and $\phi_{1}(t)$ and $\phi_{2}(t)$ are known signal expressed by the following expressions:

$$
\begin{aligned}
\phi_{1}(t) & =\dot{v}^{c}(t)-\widehat{F}(t) v(t)-\widehat{\Gamma}(t)-k_{2} e_{2}(t)-\bar{e}_{1}(t), \\
\phi_{2}(t) & =\frac{1}{\sigma L_{s}}\left(-\sigma L_{s} \frac{\pi}{h} v_{e}(t) i_{q s}(t)\right. \\
- & \left.\left(R_{s}+\left(\frac{L_{m}}{L_{r}}\right)^{2} R_{r}\right) i_{q s}(t)-\frac{P L_{m} \pi}{L_{r} h} \phi_{d r}(t) v(t)\right) .
\end{aligned}
$$

According to (26), (33), and (34), the derivative of $V_{e}$ along the dynamical trajectory of error equtaions can be computed as follows:

$$
\begin{aligned}
\dot{V}_{e} & =\bar{e}_{1}(t) \dot{\bar{e}}_{1}(t)+\bar{e}_{2}(t) \dot{\bar{e}}_{2}(t)+e_{3}(t) \dot{e}_{3}(t)+\frac{\widetilde{M}(t)}{M \gamma_{1}} \\
& \cdot \dot{\widehat{M}}(t)+\frac{\widetilde{F}(t)}{\gamma_{2}}+\frac{\dot{\hat{F}}(t)}{\gamma_{3}}=-k_{1} \bar{e}_{1}^{2}(t) \\
& -k_{2} \bar{e}_{2}^{2}(t)-k_{3} e_{3}^{2}(t)+\overline{\hat{e}}_{1}(t) \varepsilon_{2}(t)+e_{3}(t) \\
& \cdot\left(\frac{K_{T}}{M} \bar{e}_{2}(t)+\phi_{2}(t)+\frac{v_{q s}(t)}{\sigma L_{s}}-\dot{i}_{q s}^{c}(t)+k_{3} e_{3}(t)\right) \\
& +\frac{\widetilde{M}(t)}{\gamma_{1} M}\left(\dot{\hat{M}}(t)+\gamma_{1} \phi_{1}(t) \bar{e}_{2}(t)\right)
\end{aligned}
$$




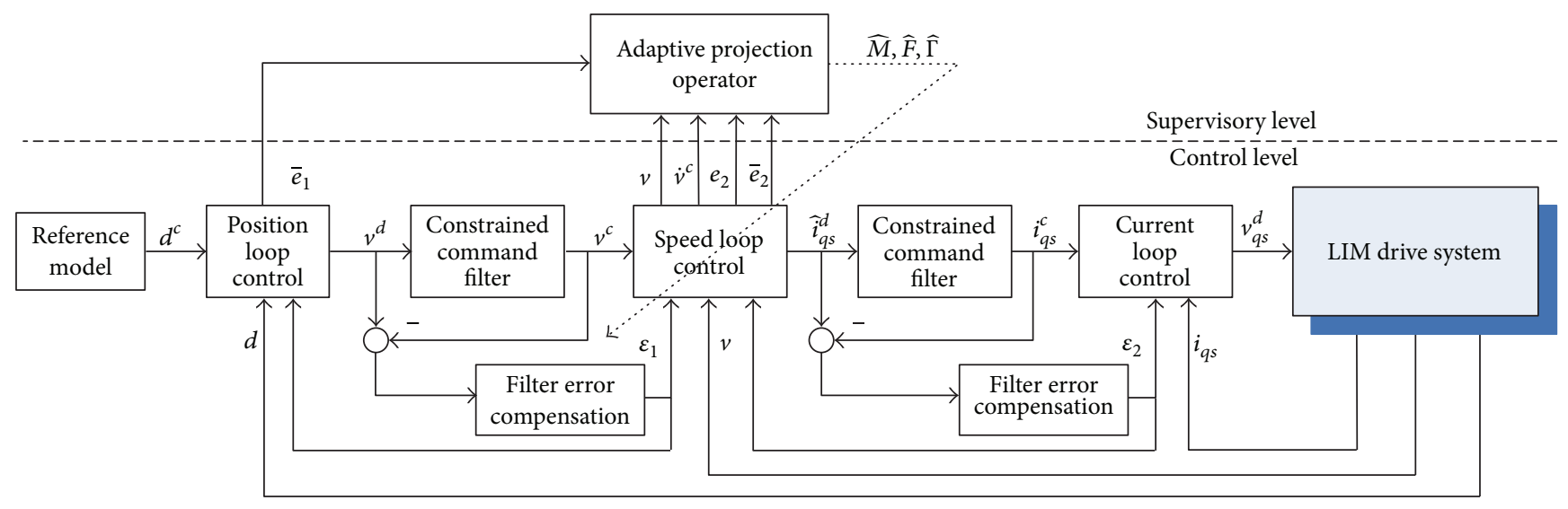

FIGURE 4: Block diagram of the proposed adaptive command-filtered backstepping via projection algorithm control.

$$
\begin{aligned}
& +\frac{\widetilde{F}(t)}{\gamma_{2}}\left(\dot{\hat{F}}(t)-\gamma_{2} \bar{e}_{2}(t) v(t)\right) \\
& +\frac{\widetilde{\Gamma}(t)}{\gamma_{3}}\left(\dot{\hat{\Gamma}}(t)-\gamma_{3} \bar{e}_{2}(t)\right) .
\end{aligned}
$$

Finally, based on (36), we can design the control law

$$
v_{q s}(t)=\sigma L_{s}\left(\dot{i}_{q s}^{c}(t)-\phi_{2}(t)-k_{3} e_{3}(t)-\frac{K_{T}}{M} \bar{e}_{2}(t)\right)
$$

and the parameter update laws as

$$
\begin{aligned}
\dot{\widehat{M}}(t) & =\gamma_{1} \operatorname{Proj}\left(\widehat{M}(t),-\phi_{1}(t) \bar{e}_{2}(t)\right), \\
\dot{\widehat{F}}(t) & =\gamma_{2} \operatorname{Proj}\left(\widehat{F}(t), \bar{e}_{2}(t) v(t)\right), \\
\dot{\widehat{\Gamma}}(t) & =\gamma_{3} \operatorname{Proj}\left(\widehat{F}(t), \bar{e}_{2}(t)\right),
\end{aligned}
$$

where $\operatorname{Proj}(\cdot, \cdot)$ is the projection operator (see the Appendix for details) which bounds that $|\widehat{M}(t)| \leq \Phi,|\widehat{F}(t)| \leq \Omega$, and $|\widehat{\Gamma}(t)| \leq \Theta$.

Using Property A.1 of the projection operator (see the Appendix for details), we can obtain that

$$
\begin{array}{r}
\widetilde{M}(t)\left[\operatorname{Proj}\left(\widehat{M}(t),-\phi_{1}(t) \bar{e}_{2}(t)\right)+\phi_{1}(t) \bar{e}_{2}(t)\right] \leq 0, \\
\widetilde{F}(t)\left[\operatorname{Proj}\left(\widehat{F}(t), \bar{e}_{2}(t) v(t)\right)-\bar{e}_{2}(t) v(t)\right] \leq 0, \\
\widetilde{\Gamma}(t)\left[\operatorname{Proj}\left(\widehat{F}(t), \bar{e}_{2}(t)\right)-\bar{e}_{2}(t)\right] \leq 0 .
\end{array}
$$

Then, according to the above analysis, we can get

$$
\dot{V}_{e}=-k_{1} \bar{e}_{1}^{2}-k_{2} \bar{e}_{2}^{2}-k_{3} e_{3}^{2}+\bar{e}_{1} \varepsilon_{2}<0,
$$

for sufficiently large $k_{1}, k_{2}, k_{3}>0$. Thus, it is proven that the whole system is asymptotically stable.

To obtain a clear idea of the overall design procedure, we give a flow chart as Figure 4.
TABLE 1: Parameters of the LIM.

\begin{tabular}{lrc}
\hline Parameter & Representation & Value \\
\hline$R_{s}(\Omega)$ & Primary resistance & 6.2689 \\
$R_{r}(\Omega)$ & Secondary resistance & 3.784 \\
$L_{m}(\mathrm{H})$ & Magnetizing inductance & 0.0825 \\
$L_{r}(\mathrm{H})$ & Secondary inductance & 0.1021 \\
$L_{s}(\mathrm{H})$ & Primary inductance & 0.1021 \\
$M(\mathrm{~kg})$ & Mass of the mover & 3.25 \\
$D(\mathrm{~kg} / \mathrm{s})$ & Viscous friction and iron-loss & 40.95 \\
$h(\mathrm{~m})$ & coefficient & 0.057 \\
$P$ & Pole pitch & 2 \\
\hline
\end{tabular}

TABLE 2: Parameters of the command filter.

\begin{tabular}{lccc}
\hline Variables & $\omega_{n}$ & Magnitude limit & Rate limit \\
\hline$v$ & 3000 & $\pm 1.5 \mathrm{~m} / \mathrm{s}$ & $\pm 50 \mathrm{~m} / \mathrm{s}^{2}$ \\
$i_{q s}$ & 3000 & $\pm 1.5 \mathrm{~A}$ & $\pm 500 \mathrm{~A} / \mathrm{s}$ \\
\hline
\end{tabular}

\section{Simulation Results}

In this section, a series of simulations are used to demonstrate the validity of the designed controller for position control of the linear induction motor in the MATLAB/Simulink environment. The parameters of the LIM model used in the dynamic simulation are summarized in Table 1 and the command filter parameters are shown in Table 2 . The rest of the parameters are selected as $k_{1}=k_{2}=k_{3}=30$ and adaptive parameters are chosen as $\gamma_{1}=0.1, \gamma_{2}=1$, and $\gamma_{3}=4000$, which is to obtain good control performance according to the need for stability of control system and adaptive algorithm.

At first, periodic step command is used to test the stability and robustness of the control system with constant load force $50 \mathrm{~N}$ occurring at $2 \mathrm{~s}$. Figure 5 shows the periodic step reference and its tracking response, the tracking error, and the related control efforts $i_{q s}$ and $F_{e}$. From the simulation results, the proposed control scheme for position control of the LIM has satisfactory control performance (a minimum response 

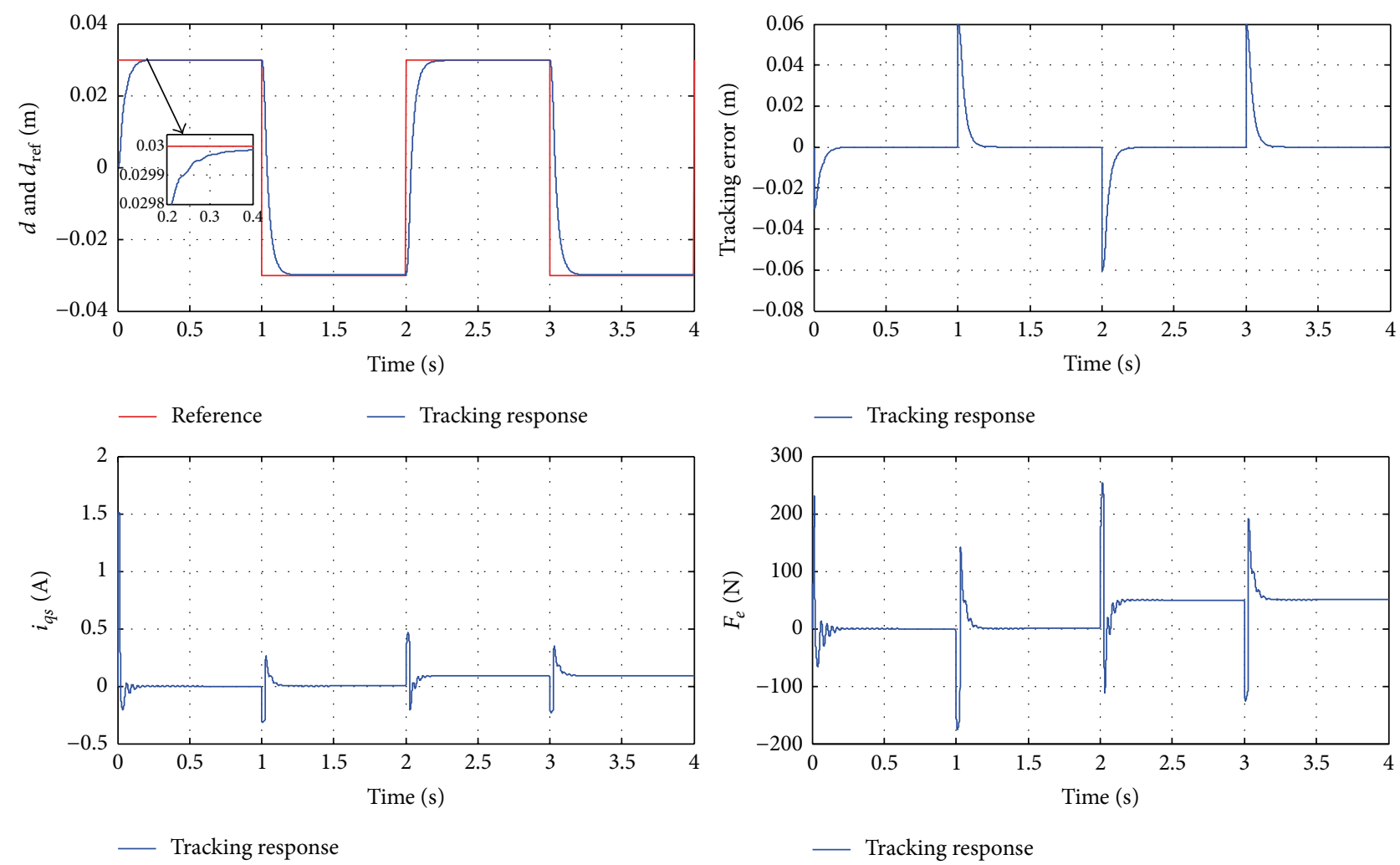

FIGURE 5: Simulation results of adaptive command-filtered backstepping via projection algorithm for LIM period step signal position control with constant load force $50 \mathrm{~N}$ at $2 \mathrm{~s}$.

time and being without overshot and minimal tracking error) against the external load disturbance. In order to further demonstrate the performance of the designed controller, periodic triangular and sinusoidal reference command with constant load force $50 \mathrm{~N}$ occurring at $2 \mathrm{~s}$ are used in the simulations and the simulated results are, respectively, shown in Figures 6 and 7. From the simulation results of Figures 6 and 7 , the designed control system still has a desired tracking performance under the condition of the sudden change of load force.

Then, the simulated results of the period position response with the periodic triangular and sinusoidal external disturbance occurring at $2 \mathrm{~s}$ are shown in Figures 8 and 9, respectively. According to the simulation results, we can clearly find that the tracking error changes little and the proposed control has a satisfactory performance in spite of the time-varying load disturbance, which further supports the effectiveness of the designed controller.

Thirdly, we compare the command-filtered backstepping control (CBC) and adaptive command-filtered backstepping via projection algorithm control under the same conditions of sinusoidal variation of load disturbance. The simulation results of the periodic step signal tracking, triangular signal tracking, and sinusoidal signal tracking and their tracking errors are, respectively, shown in Figures 10, 11, and 12. From them, we can obviously draw that the tracking performance of the designed controller is better compared to the $\mathrm{CBC}$ under the condition of the external disturbance of load.
Fourthly, Figure 13 shows the estimated parameters $\widehat{M}$, $\widehat{F}$, and $\widehat{\Gamma}$ under normal drive circumstance of the LIM. From the simulation results, it can be clearly observed that the estimated parameters converge to the true values, which also explains the robustness of the proposed adaptive control.

Fifthly, output limit amplitudes $v, \dot{v}, i_{q s}$, and $i_{q s}$ of the command filter in the case of periodic step tracking with constant load force $50 \mathrm{~N}$ occurring at $2 \mathrm{~s}$ are shown in Figure 14.

\section{Conclusion}

A theoretical framework for the position control is developed and applied to the LIM in this paper. To achieve satisfactory robustness and stability, a command-filtered backstepping control with adaptive function approximation is designed. First, Lyapunov stability theory ensures uniformly bounded tracking errors under the condition of the time-varying external disturbances. At the same time, command filter solves the differential expansion and the control saturation problems in the backstepping, and compensating signals are presented to eliminate the influence of the errors caused by command filters. Then, projection-based adaptive method is used to obtain the robustness against the parameter uncertainties. It is worth mentioning that the proposed control scheme is suitable when the explicit model of LIM is hard to obtain. Finally, simulation results proved that the proposed nonlinear adaptive controller has satisfactory control performance and 

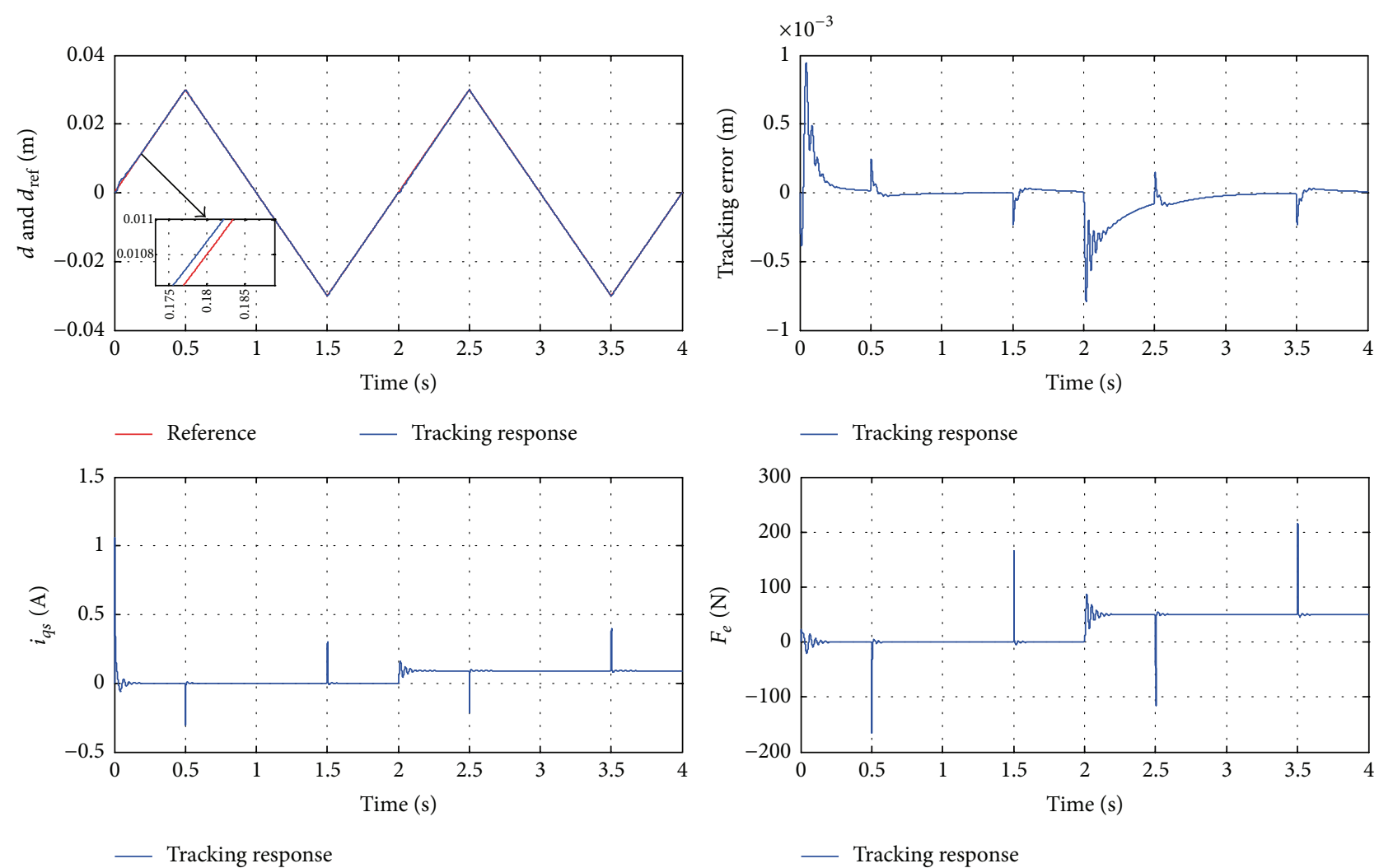

FIGURE 6: Simulation results of adaptive command-filtered backstepping via projection algorithm for LIM period triangular signal position control with constant load force $50 \mathrm{~N}$ at $2 \mathrm{~s}$.
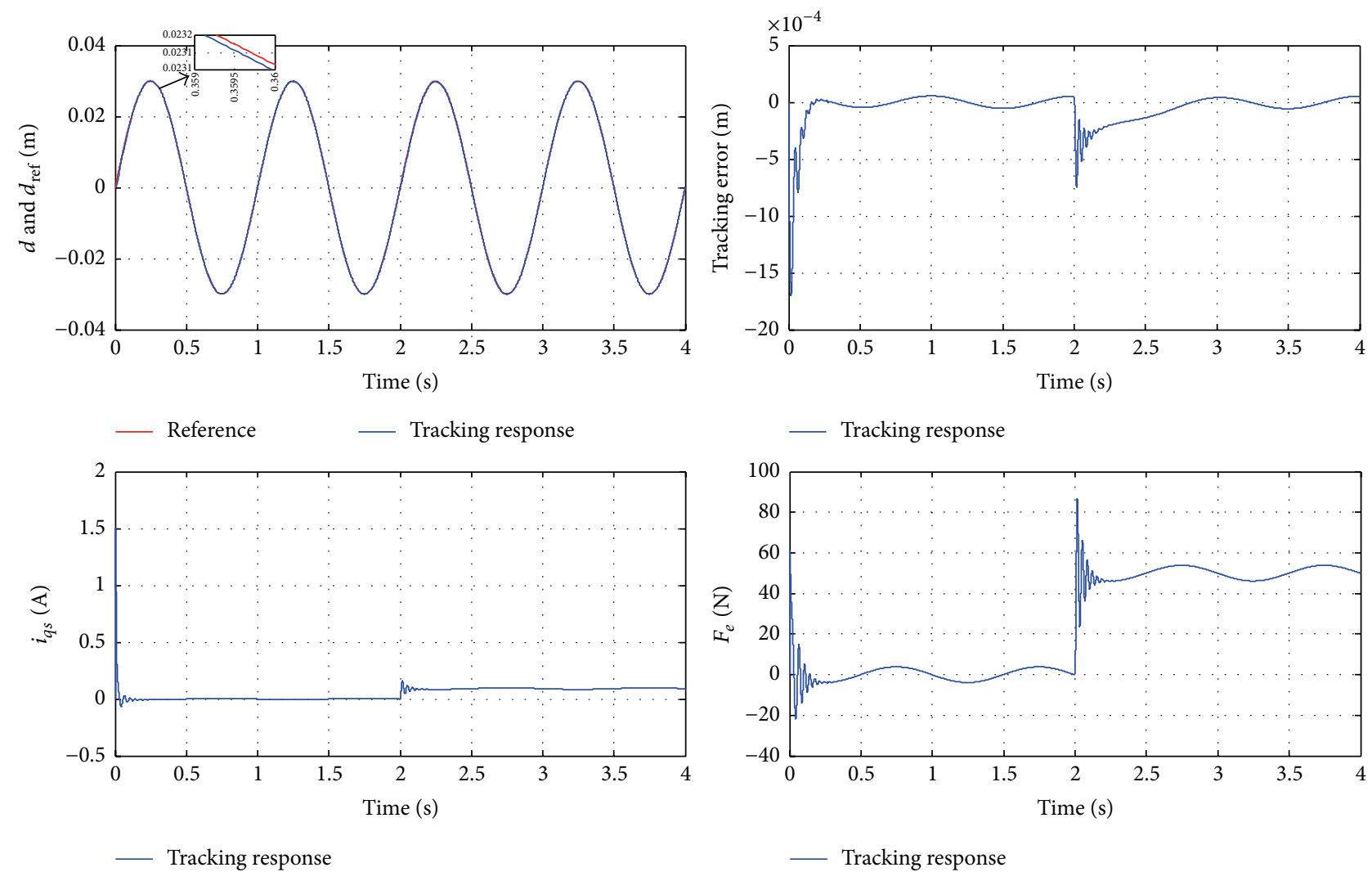

FIGURE 7: Simulation results of adaptive command-filtered backstepping via projection algorithm for LIM period sinusoidal signal position control with constant load force $50 \mathrm{~N}$ at $2 \mathrm{~s}$. 

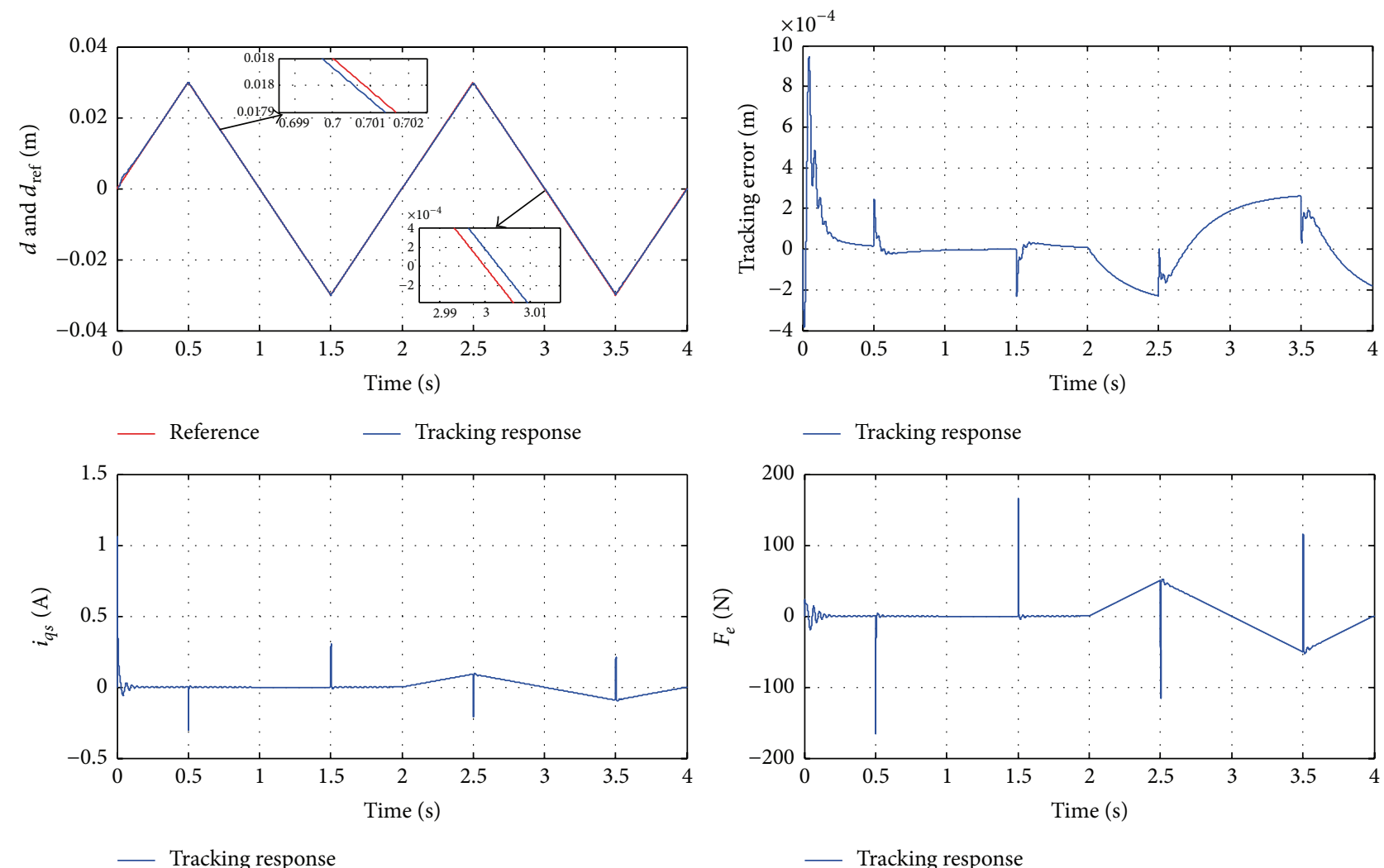

FIGURE 8: Simulation results of adaptive command-filtered backstepping via projection algorithm for LIM triangular signal position control with periodic triangular load force at $2 \mathrm{~s}$.
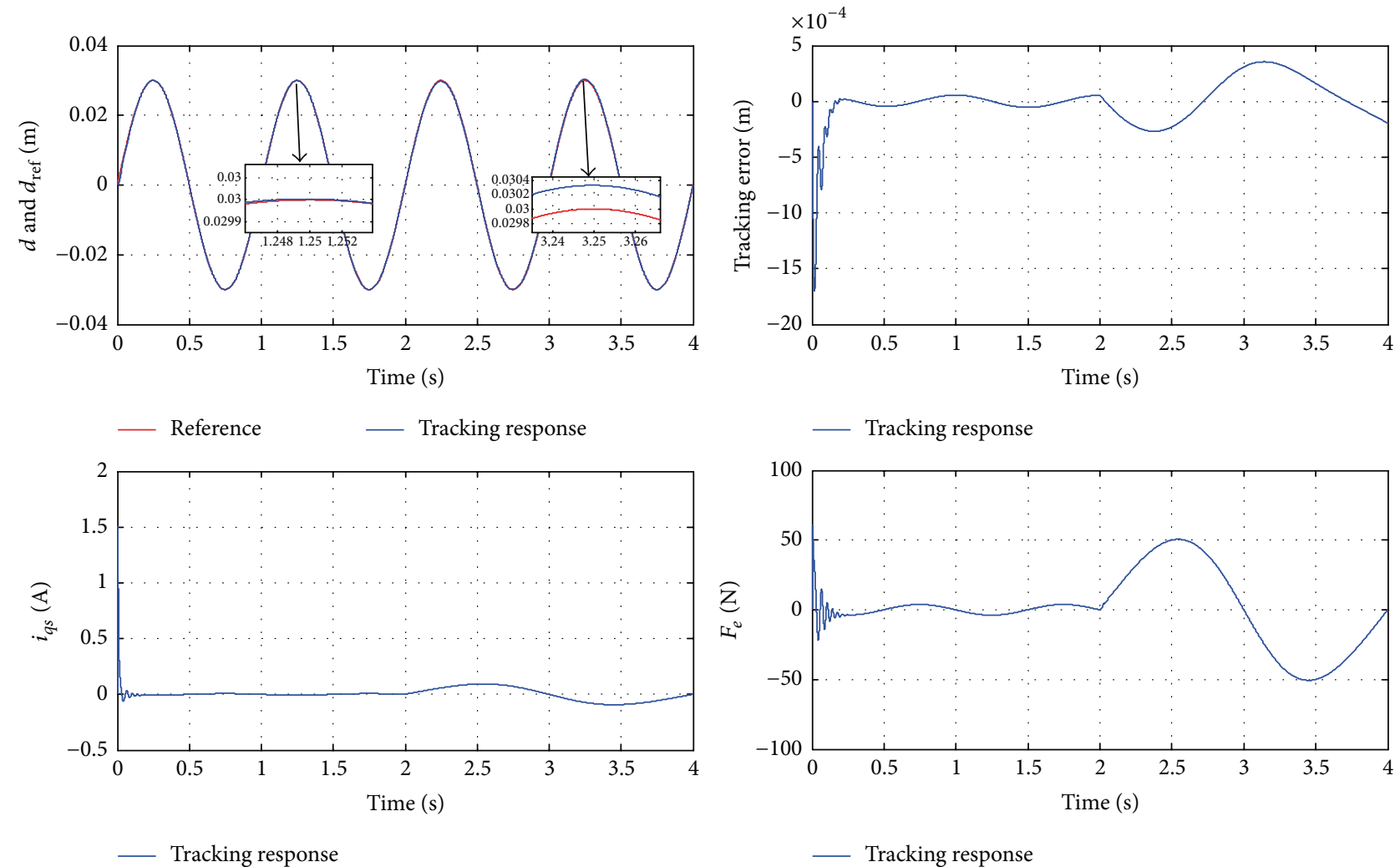

FIGURE 9: Simulation results of adaptive command-filtered backstepping via projection algorithm control for LIM sinusoidal signal position control with periodic sinusoidal load force at $2 \mathrm{~s}$. 

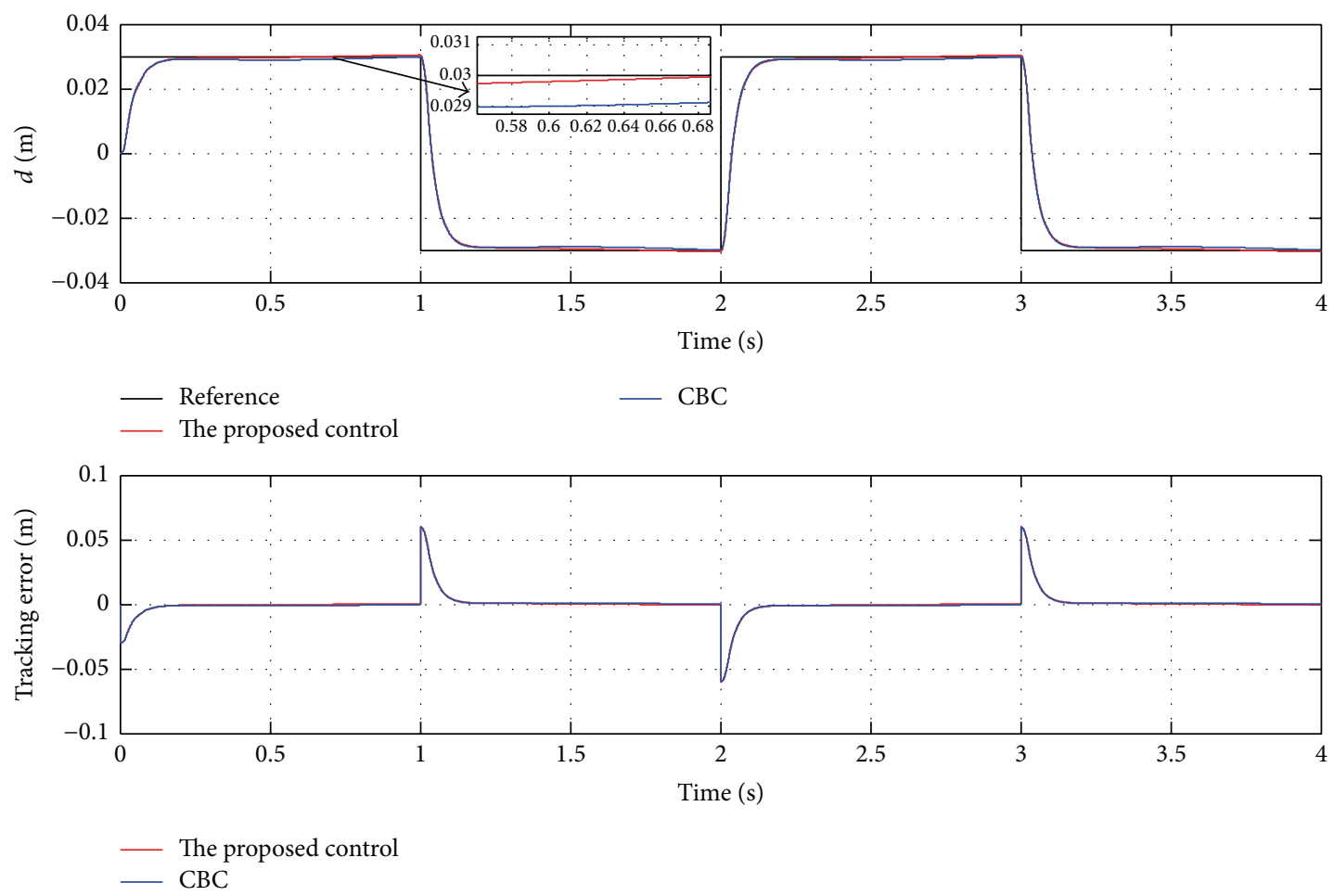

FIGURE 10: Comparison of the simulation results between the proposed adaptive control and CBC for the LIM periodic step signal position tracking with periodic sinusoidal load force.
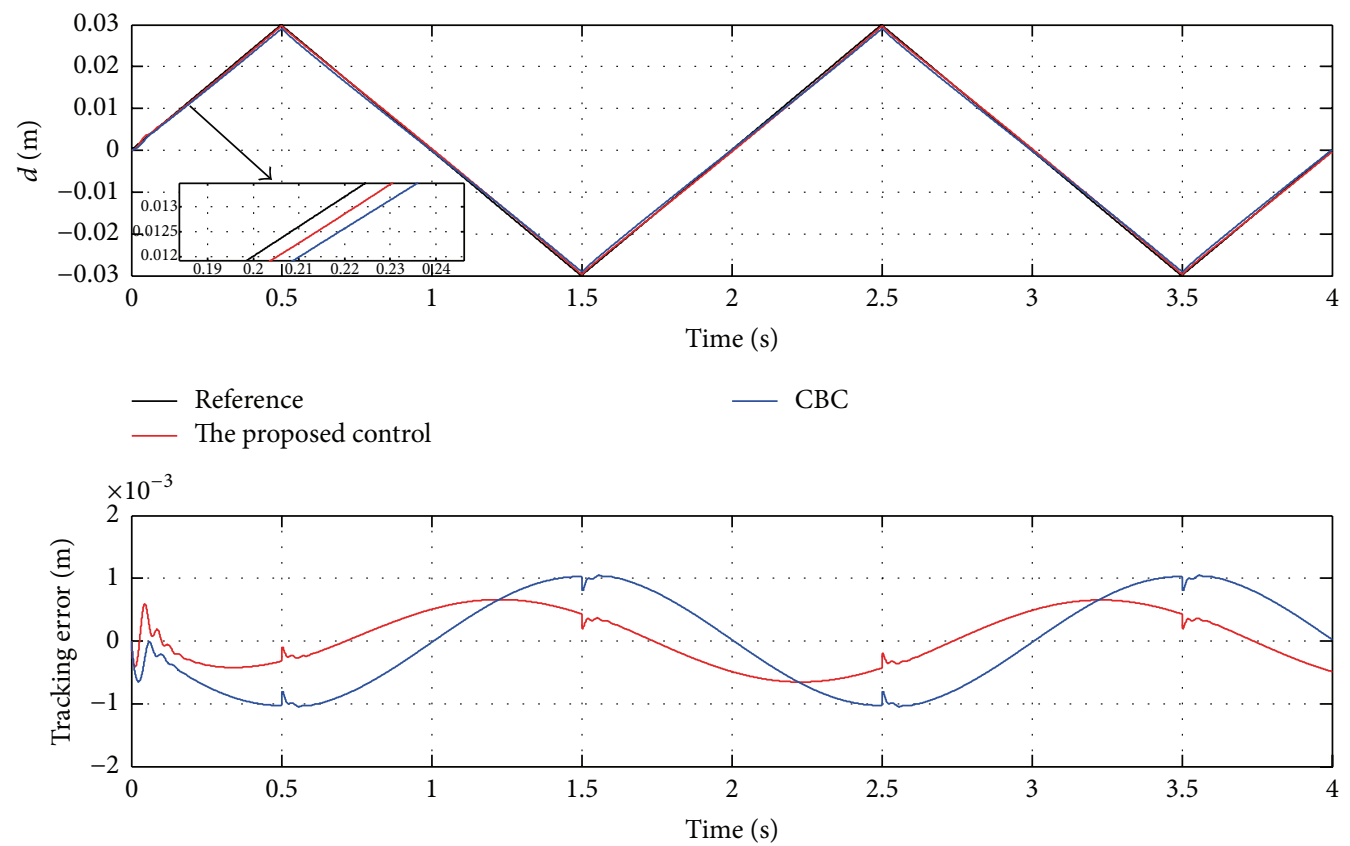

- The proposed control

FIGURE 11: Comparison of the simulation results between the proposed adaptive control and CBC for the LIM periodic triangular signal position tracking with periodic sinusoidal load force. 

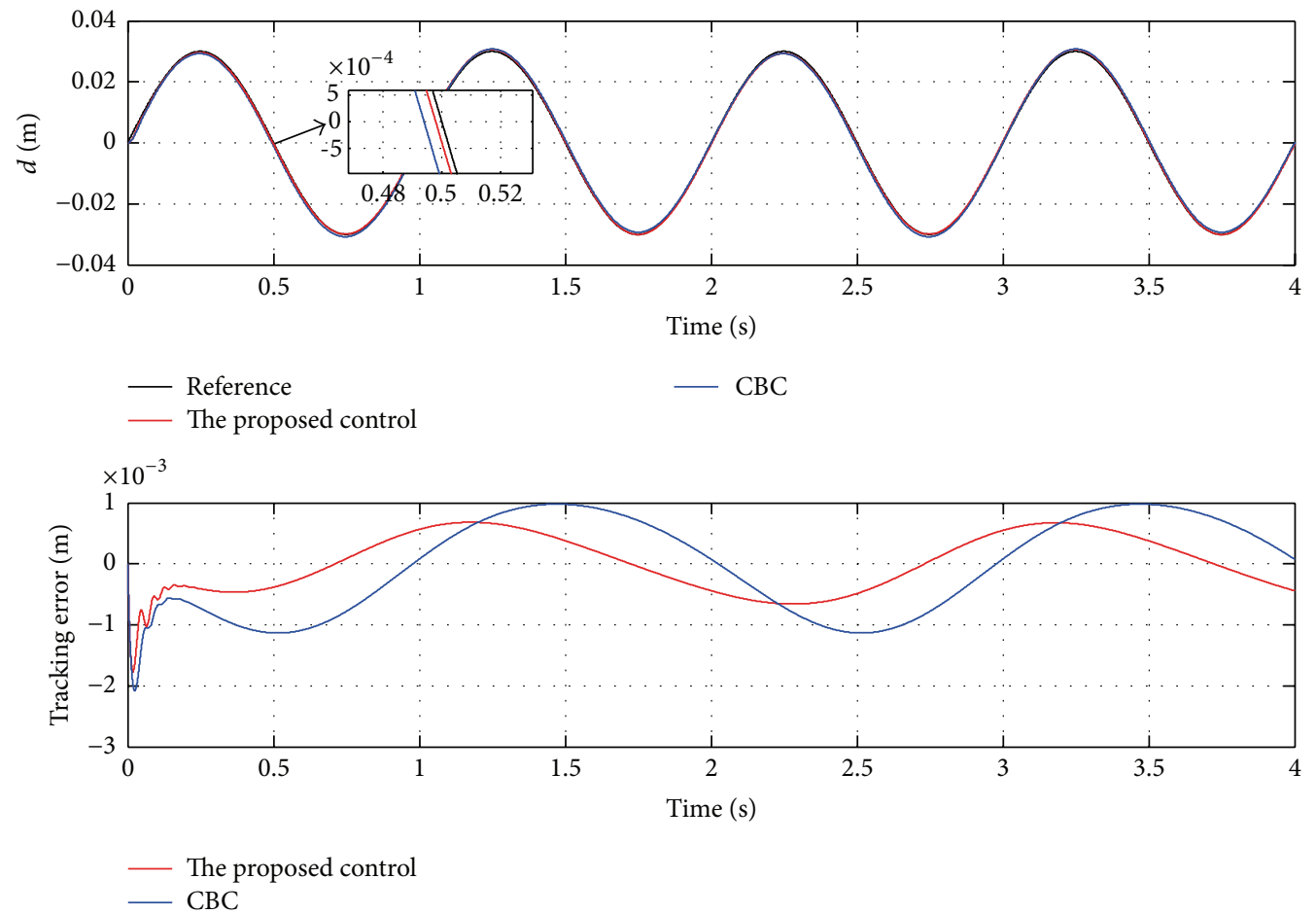

FIGURE 12: Comparison of the simulation results between the proposed adaptive control and CBC for the LIM periodic sinusoidal signal position tracking with periodic sinusoidal load force.
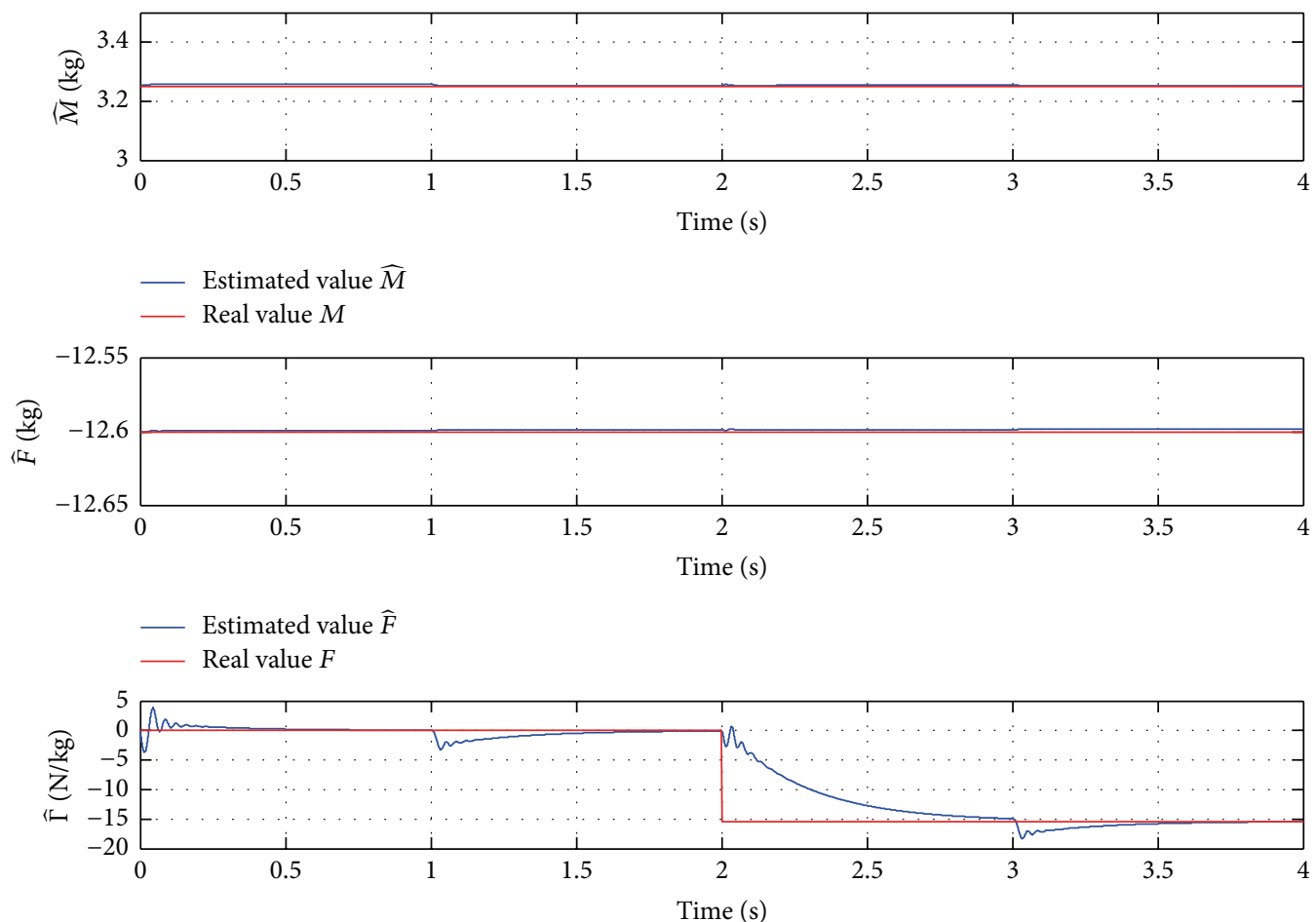

Estimated value $\widehat{\Gamma}$

Real value $\Gamma$

FIGURE 13: Estimated parameters $\widehat{M}, \widehat{F}$, and $\widehat{\Gamma}$ under normal drive circumstance. 

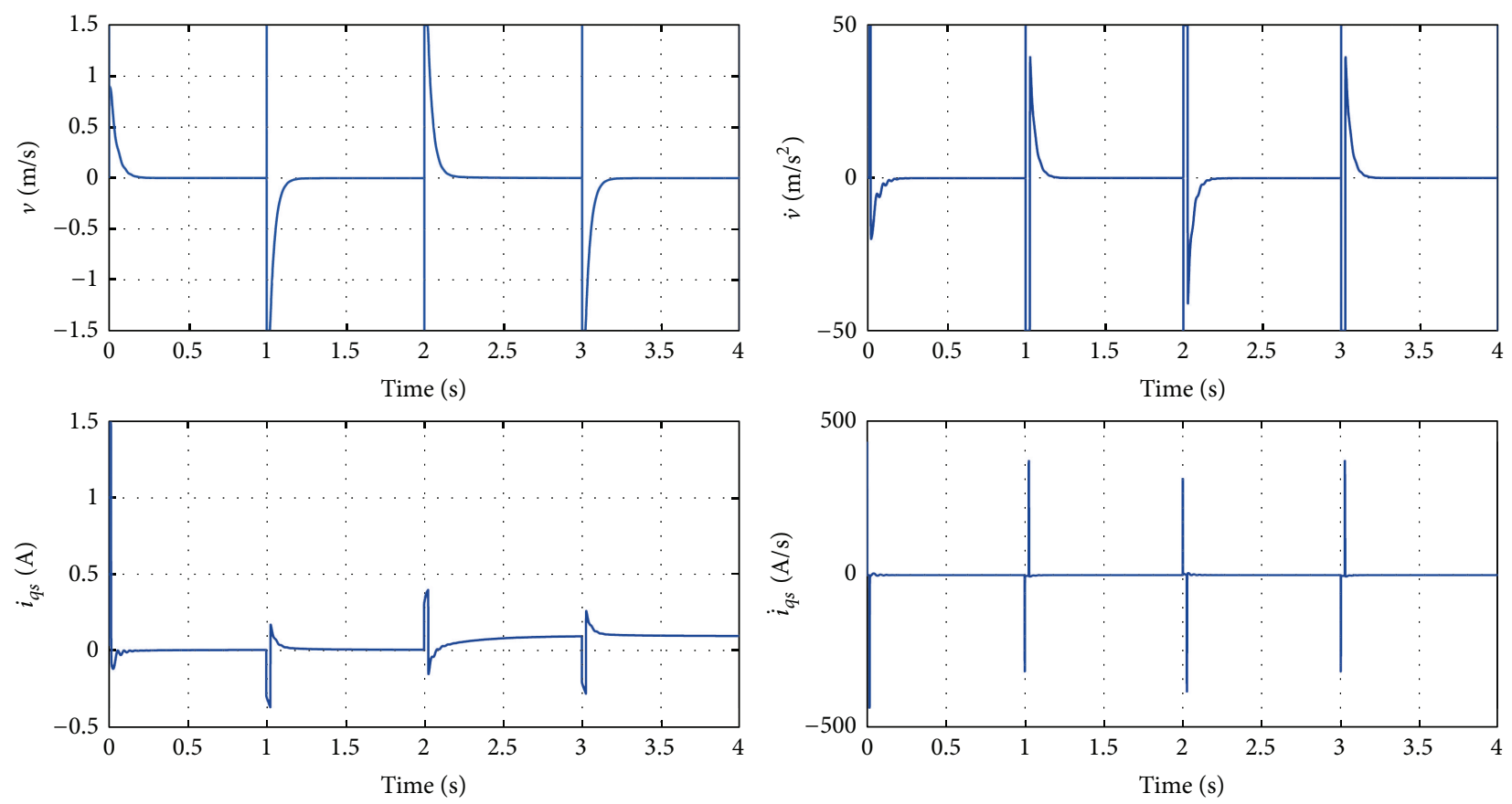

FIGURE 14: Output limit amplitudes $v, \dot{v}$, and $i_{q s}$ in the command filter.

robustness against the parameter uncertainties and the timevarying external disturbances.

\section{Appendix}

The smoothened projection operator introduced in [31] bounds the estimated parameters by definition. The projection operator is useful for robust adaptive controller which needs multiple differentiations of the adaptation law in backstepping. Then we review the main definitions and property from [31].

Definition A.1. The parameter vector $\boldsymbol{\theta}$ belongs to a convex compact set given by

$$
\Omega=\left\{\|\boldsymbol{\theta}\| \leq \boldsymbol{\theta}_{\max }\right\}
$$

where $\boldsymbol{\theta}_{\max }$ is the norm bound of vector $\boldsymbol{\theta}$. For any given $\mathbf{x} \epsilon$ $R^{n}$, the standard Lipschitz continuous projection operator is defined as

$$
\begin{aligned}
\dot{\hat{\boldsymbol{\theta}}} & =\operatorname{Proj}(\widehat{\boldsymbol{\theta}}, \mathbf{x}) \\
& = \begin{cases}\mathbf{x}, & \text { if } f(\widehat{\boldsymbol{\theta}})<0 \\
\mathbf{x}, & \text { if } f(\widehat{\boldsymbol{\theta}}) \geqslant 0, \nabla f(\widehat{\boldsymbol{\theta}})^{T} \mathbf{x} \leq 0 \quad \text { (A.2) } \\
\mathbf{x}-\frac{\nabla f(\widehat{\boldsymbol{\theta}}) f(\widehat{\boldsymbol{\theta}})^{T} \mathbf{x}}{\|f(\widehat{\boldsymbol{\theta}})\|^{2}} f(\widehat{\boldsymbol{\theta}}), & \text { otherwise, }\end{cases}
\end{aligned}
$$

where $\nabla$ is the gradient vector of $f(\cdot)$ calculated at $\widehat{\boldsymbol{\theta}}$ and $f(\cdot)$ : $R^{n} \rightarrow R$ is following the convex smooth function:

$$
f(\widehat{\boldsymbol{\theta}})=\frac{\widehat{\boldsymbol{\theta}}^{T} \widehat{\boldsymbol{\theta}}-\boldsymbol{\theta}_{\max }}{\varepsilon^{2}+2 \varepsilon \boldsymbol{\theta}_{\max }}
$$

where $\varepsilon$ is an arbitrary positive.

The property of the projection operator has been proven in [31], described as follows.

Property A.1. If we choose $\widehat{\boldsymbol{\theta}}(0) \in \Omega$ and let the parameter $\widehat{\boldsymbol{\theta}}(t)$ evolve according to the following dynamics:

$$
\dot{\hat{\boldsymbol{\theta}}}(t)=\operatorname{Proj}(\widehat{\boldsymbol{\theta}}(t), \mathbf{x}), \quad \widehat{\boldsymbol{\theta}}\left(t_{0}\right) \in \Omega,
$$

then

$$
\widehat{\boldsymbol{\theta}}(t) \in \Omega \text {. }
$$

For all $t \geqslant t_{0}$, the following inequality is established as follows:

$$
(\widehat{\boldsymbol{\theta}}-\boldsymbol{\theta})^{T} \operatorname{Proj}(\widehat{\boldsymbol{\theta}}, \mathbf{x}) \leq(\widehat{\boldsymbol{\theta}}-\boldsymbol{\theta})^{T} \mathbf{x} .
$$

\section{Competing Interests}

The authors declare that they have no competing interests.

\section{Acknowledgments}

This work is supported by National Natural Science Foundation of China $(61503156,51405198)$ and the Fundamental Research Funds for the Central Universities (JUSRP11562, NJ20150011). 


\section{References}

[1] M. R. Doyle, D. J. Samuel, T. Conway, and R. R. Klimowski, "Electromagnetic aircraft launch system-EMALS," IEEE Transactions on Magnetics, vol. 31, no. 1, pp. 528-533, 1995.

[2] H. S. Lim and R. Krishnan, "Ropeless elevator with linear switched reluctance motor drive actuation systems," IEEE Transactions on Industrial Electronics, vol. 54, no. 4, pp. 22092218, 2007.

[3] G. W. McLean, "Review of recent progress in linear motors," IEE Proceedings B-Electric Power Applications, vol. 135, no. 6, pp. 380-416, 1988.

[4] J. Gustafsson, "Vectus-intelligent transport," Proceedings of the IEEE, vol. 97, no. 11, pp. 1856-1863, 2009.

[5] H. Gurol, "General atomics linear motor applications: Moving towards deployment," Proceedings of the IEEE, vol. 97, no. 11, pp. 1864-1871, 2009.

[6] J. Fang, D. B. Montgomery, and L. Roderick, "A novel magpipe pipeline transportation system using linear motor drives," Proceedings of the IEEE, vol. 97, no. 11, pp. 1848-1855, 2009.

[7] R. Hellinger and P. Mnich, "Linear motor-powered transportation: history, present status, and future outlook," Proceedings of the IEEE, vol. 97, no. 11, pp. 1892-1900, 2009.

[8] I. Takahashi and Y. Ide, "Decoupling control of thrust and attractive force of a LIM using a space vector control inverter," IEEE Transactions on Industry Applications, vol. 29, no. 1, pp. 161-167, 1993.

[9] I. Boldea and S. A. Nasar, "Linear electric actuators and generators," IEEE Transactions on Energy Conversion, vol. 14, no. 3, pp. 712-717, 1999.

[10] F.-J. Lin and C.-C. Lee, "Adaptive backstepping control for linear induction motor drive to track periodic references," IEE Proceedings-Electric Power Applications, vol. 147, no. 6, pp. 449-458, 2000.

[11] A. Accetta, M. Cirrincione, M. Pucci, and G. Vitale, "Neural sensorless control of linear induction motors by a full-order luenberger observer considering the end effects," IEEE Transactions on Industry Applications, vol. 50, no. 3, pp. 1891-1904, 2014.

[12] G. Kang and K. Nam, "Field-oriented control scheme for linear induction motor with the end effect," IEE Proceedings-Electric Power Applications, vol. 152, no. 6, pp. 1565-1572, 2005.

[13] R.-J. Wai and C.-C. Chu, "Motion control of linear induction motor via Petri fuzzy neural network," IEEE Transactions on Industrial Electronics, vol. 54, no. 1, pp. 281-295, 2007.

[14] C.-M. Lin and C.-F. Hsu, "Recurrent-neural-network-based adaptive-backstepping control for induction servomotors," IEEE Transactions on Industrial Electronics, vol. 52, no. 6, pp. 1677-1684, 2005.

[15] I. Kanellakopoulos, P. V. Kokotovic, and A. S. Morse, "Systematic design of adaptive controllers for feedback linearizable systems," in Proceedings of the American Control Conference, pp. 649-654, Boston, Mass, USA, June 1991.

[16] Z.-Y. Sun, Z.-G. Liu, and X.-H. Zhang, "New results on global stabilization for time-delay nonlinear systems with low-order and high-order growth conditions," International Journal of Robust and Nonlinear Control, vol. 25, no. 6, pp. 878-899, 2015.

[17] Z.-Y. Sun, X.-H. Zhang, and X.-J. Xie, "Continuous global stabilisation of high-order time-delay nonlinear systems," International Journal of Control, vol. 86, no. 6, pp. 994-1007, 2013.
[18] Z.-Y. Sun, Z.-B. Song, T. Li, and S.-H. Yang, "Output feedback stabilization for high-order uncertain feedforward time-delay nonlinear systems," Journal of the Franklin Institute. Engineering and Applied Mathematics, vol. 352, no. 11, pp. 5308-5326, 2015.

[19] R.-J. Wai, F.-J. Lin, and S.-P. Hsu, "Intelligent backstepping control for linear induction motor drive," IEE ProceedingsControl Theory and Applications, vol. 148, no. 3, pp. 193-202, 2001.

[20] A. Boucheta, I. K. Bousserhane, A. Hazzab, B. Mazari, and M. K. Fellah, "Adaptive backstepping controller for linear induction motor position control," COMPEL, vol. 29, no. 3, pp. 789-810, 2010.

[21] F. Mazenc and P.-A. Bliman, "Backstepping design for timedelay nonlinear systems," IEEE Transactions on Automatic Control, vol. 51, no. 1, pp. 149-154, 2006.

[22] Z.-Y. Sun, T. Li, and S.-H. Yang, "A unified time-varying feedback approach and its applications in adaptive stabilization of high-order uncertain nonlinear systems," Automatica, vol. 70, no. 8, pp. 249-257, 2016.

[23] Z.-Y. Sun, L.-R. Xue, and K. Zhang, "A new approach to finitetime adaptive stabilization of high-order uncertain nonlinear system," Automatica, vol. 58, no. 8, pp. 60-66, 2015.

[24] H.-H. Chiang, K.-C. Hsu, and I.-H. Li, "Optimized adaptive motion control through an SoPC implementation for linear induction motor drives," IEEE/ASME Transactions on Mechatronics, vol. 20, no. 1, pp. 348-360, 2015.

[25] Z.-Y. Sun and Y.-G. Liu, "Adaptive control design for a class of uncertain high-order nonlinear systems with time delay," Asian Journal of Control, vol. 17, no. 2, pp. 535-543, 2015.

[26] J. Yu, P. Shi, W. Dong, B. Chen, and C. Lin, "Neural networkbased adaptive dynamic surface control for permanent magnet synchronous motors," IEEE Transactions on Neural Networks and Learning Systems, vol. 26, no. 3, pp. 640-645, 2015.

[27] Q. Shen and P. Shi, "Distributed command filtered backstepping consensus tracking control of nonlinear multiple-agent systems in strict-feedback form," Automatica. A Journal of IFAC, the International Federation of Automatic Control, vol. 53, pp. 120 124, 2015.

[28] J. Yu, P. Shi, W. Dong, and H. Yu, "Observer and commandfilter-based adaptive fuzzy output feedback control of uncertain nonlinear systems," IEEE Transactions on Industrial Electronics, vol. 62, no. 9, pp. 5962-5970, 2015.

[29] W. Dong, J. A. Farrell, M. M. Polycarpou, V. Djapic, and M. Sharma, "Command filtered adaptive backstepping," IEEE Transactions on Control Systems Technology, vol. 20, no. 3, pp. 566-580, 2012.

[30] J. A. Farrell, M. Polycarpou, M. Sharma, and W. Dong, "Command filtered backstepping," IEEE Transactions on Automatic Control, vol. 54, no. 6, pp. 1391-1395, 2009.

[31] Z. Cai, M. S. De Queiroz, and D. M. Dawson, "A sufficiently smooth projection operator," IEEE Transactions on Automatic Control, vol. 51, no. 1, pp. 135-139, 2006. 


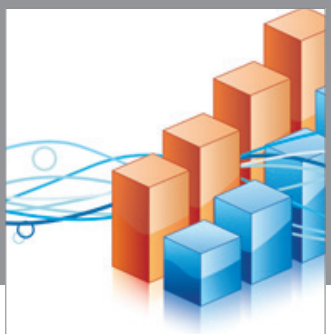

Advances in

Operations Research

vatem alat4

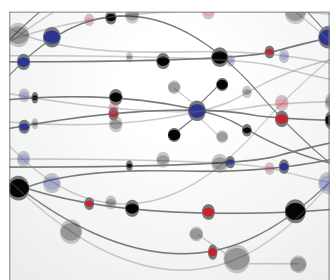

\section{The Scientific} World Journal
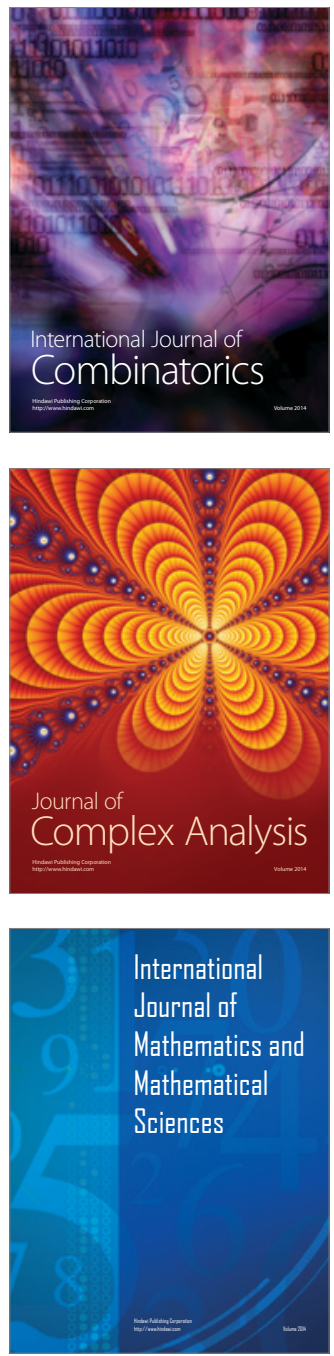
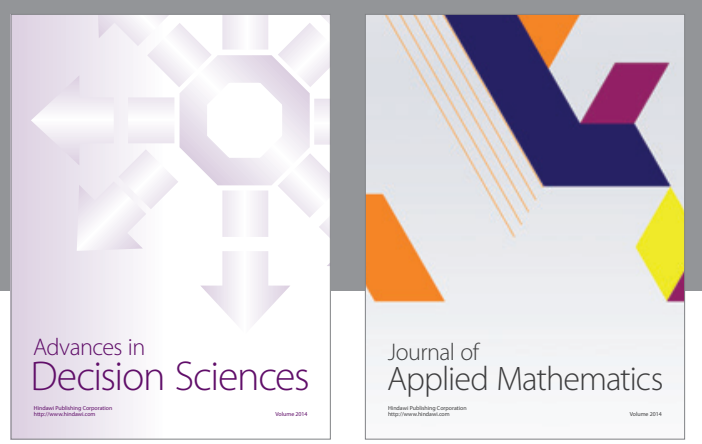

Algebra

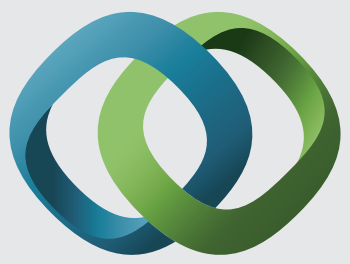

\section{Hindawi}

Submit your manuscripts at

http://www.hindawi.com
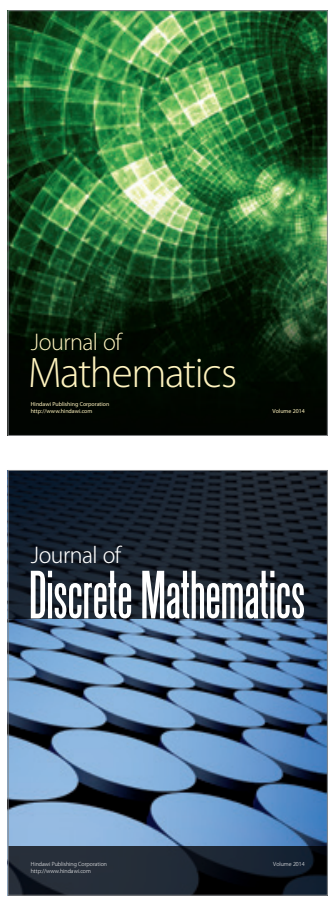

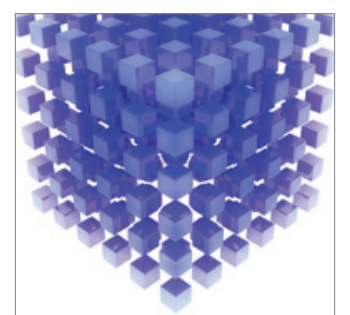

Mathematical Problems in Engineering
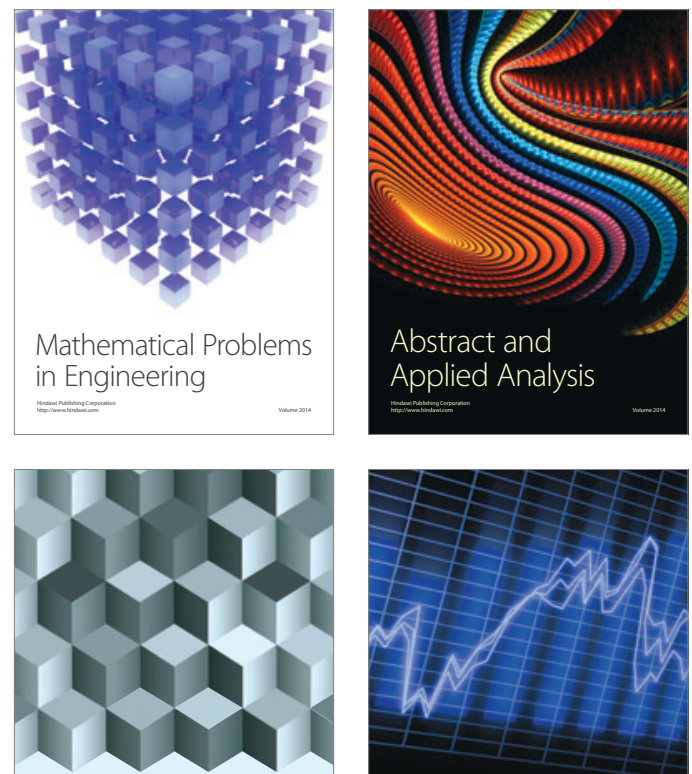

Journal of

Function Spaces

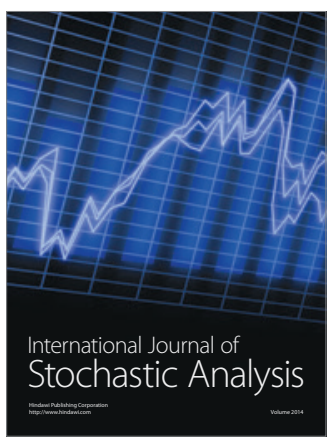

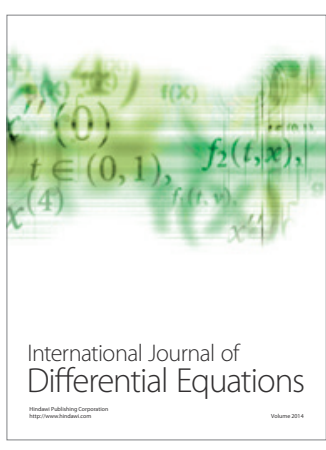
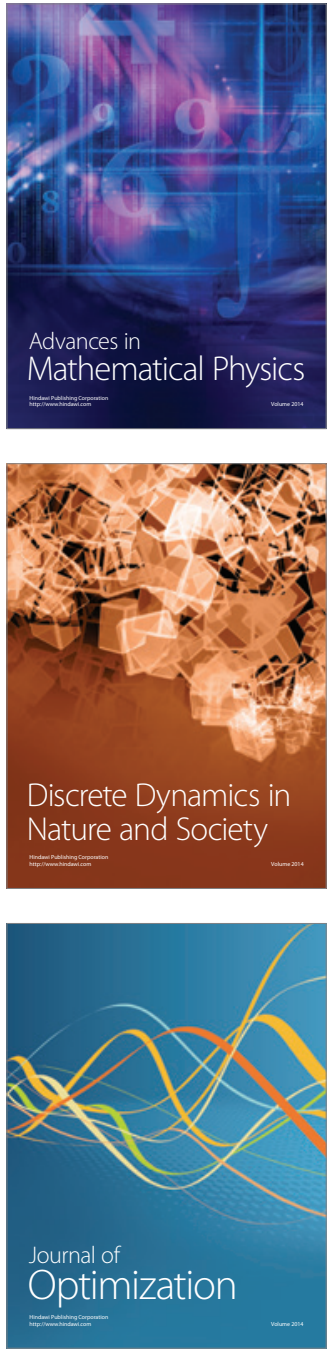